DOI 10.17816/transsyst20184365-71

\author{
(C) R. Rampelmann, R. Köhler \\ Thyssenkrupp Transrapid GmbH \\ (Munich, Germany)
}

\title{
SERVICE EXPERIENCES MAGLEV VEHICLES SHANGHAI
}

\begin{abstract}
In the late 1990s thyssenkrupp Transrapid GmbH successfully qualified the Maglev Vehicle TR08 and obtained the type approval certificate. Based on that design, in 20012003 three five-car vehicles for the first commercial high speed Maglev Line in Shanghai have been manufactured and set into operation. The VIP-Run took place over 15 years ago and the commercial operation has been running for almost 15 years at great availability.

The Transrapid system concept of small autonomous redundant electronics based modules facilitates significantly smooth maintenance - diagnosis, testing and system inspection.

Thanks to intelligent diagnostics, the use of easily interchangeable plug-in units, the dimensioning of the spare parts inventory according to the expected failure rates and the replenishment lead time, the maintenance efforts are still within the forecast range at the beginning of the project. Furthermore, the maintenance concept is essentially unchanged since the beginning.

There are no special materials that are subject to a potential shortage or price leap, but all according to normal industrial base.

Thanks to the low level of stress to components on board, most electrical and electronic units are still on-board as original equipment, which are 15 years old and at no end of life is visible.

But in case of repair or replacement, the challenge is the adaptation to the volatile market of electronic components. This includes the necessary lead-time for adaptive development and qualification, which has to be considered.

On the side of the vehicle supplier, a small smart team of electronics experts is managing obsolescence and compensates discontinuation.

The paper tells how it works and appreciates trustful cooperation of the supplier in Europe with the operator in China.
\end{abstract}

Keywords: Maglev vehicle, Service, Spare parts strategy, Maintenance, Obsolescence, Electronic components.

\section{INTRODUCTION}

The article first provides the key data of the Shanghai Maglev Transportation Project, then highlights some main features of the Transrapid system and especially the vehicle to end with a detailed description of the maintenance procedures and experiences for the vehicles up to now. 


\section{SHANGHAI MAGLEV TRANSPORTATION PROJECT}

The Shanghai project is in all, a real story of success. In only three years, the total project, from the signing of contracts to the start of commercial operation, was finished. Fig. 1 shows the timeline for the realization of the Shanghai Project.

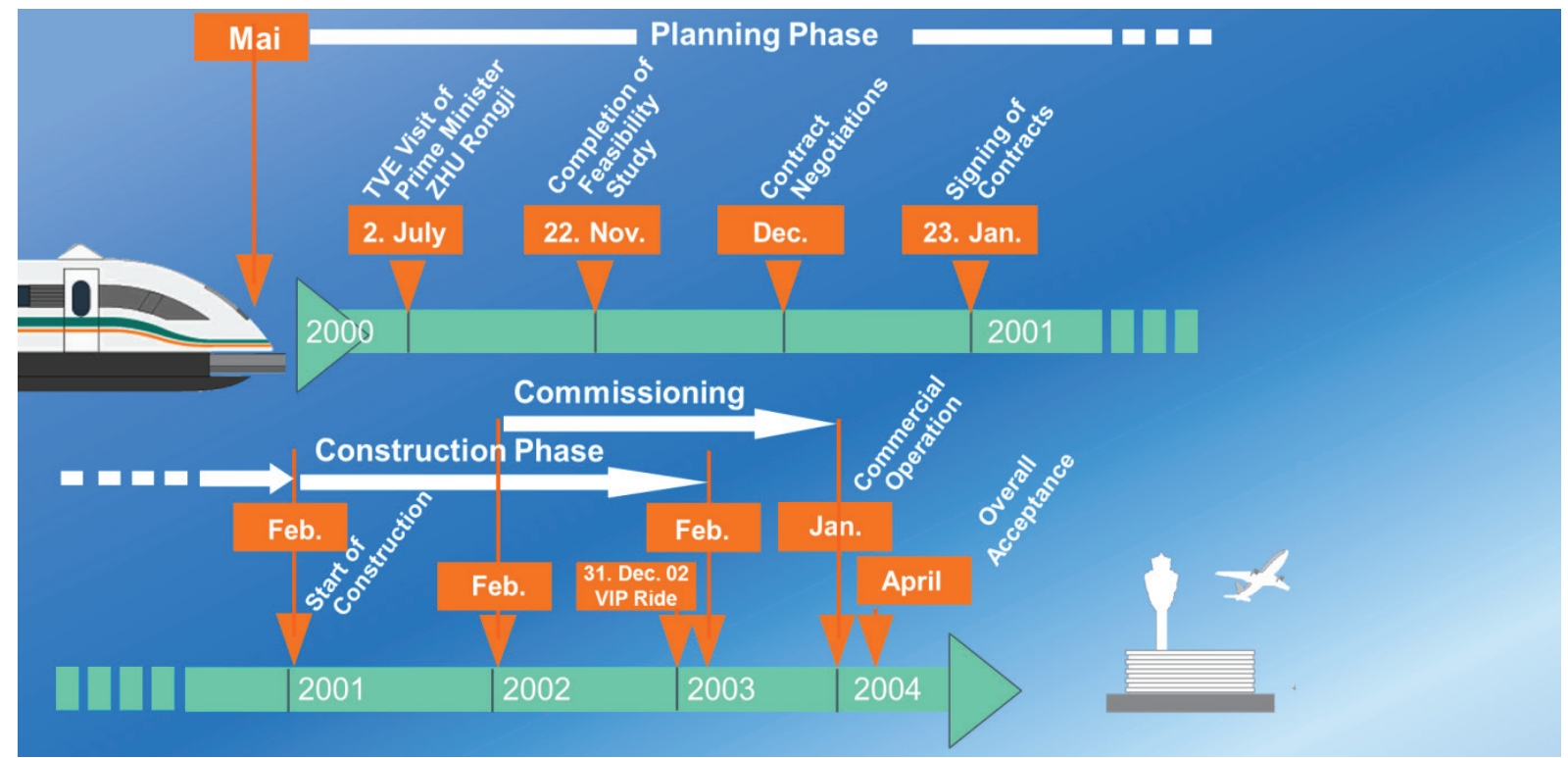

Fig. 1. Timeline of the Shanghai Maglev Project

Fig. 2 shows the track scheme and the main data. The technical layout like platform length and maintenance tracks is made for eight car trains. The operation control system and the propulsion system allow a frequency of one train every ten minutes. So the system is ready for further increase in passenger demand. For the time being five car trains and fifteen minute headway are used for operation.

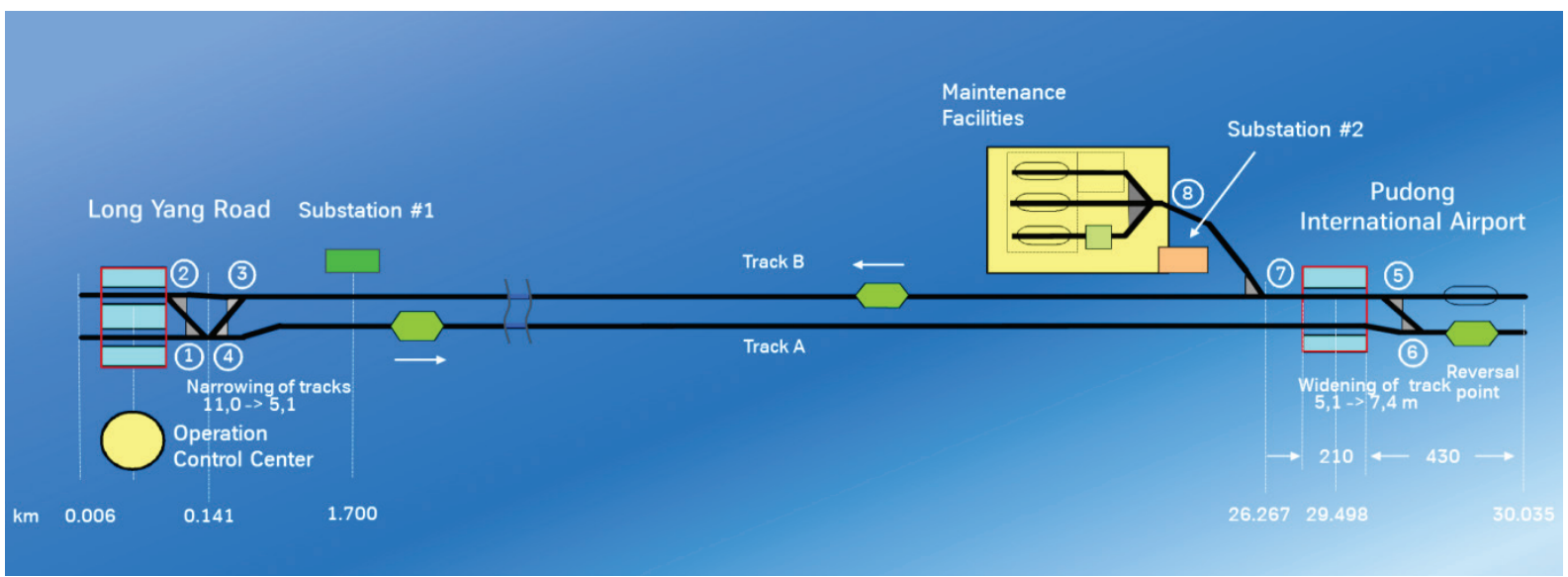

Fig. 2. Track scheme of the Shanghai Maglev Project 


\section{TRANSRAPID SYSTEM CONCEPT}

Fourteen years of operation after acceptance in April 2004 and sixteen years of system operation after start of commissioning in September 2002 represent a time period already nearing half of the 35 years life span Maglev vehicles are designed for. This is now a good time to have a technical review and outlook.

There is one basic principle of the system design which is still absolutely valid: the redundancy in such a way that any failure in any active component (vehicle, propulsion, or operations control) allows to continue service for a tolerable predefined time and that there is no need to stop the system running.

Also the key functions of levitation, guidance, and eddy-current safety brake are based on active safe-life strategy. So it never occurred that a vehicle stopped and could not become levitating due to failure.

Now, the actual experience with Transrapid vehicles and many other electronic applications have clearly proven the benefit and availability of systems mainly based on electronics. In fact, today many experts state electronics being a precondition to achieve extreme reliability and availability.

Another important design feature is the diagnosis system for the precise detection of failures to reduce maintenance time by clearly indicating the type and location of a failure

Dominant use of quickly replaceable slide-in units with short replacement time reduces maintenance measures and time at system level to a minimum, defective components are tested and repaired off-line without influencing system availability.

Fig. 3 shows the exchange of a slide-in unit that can be handled by two persons and is accomplished very quickly.

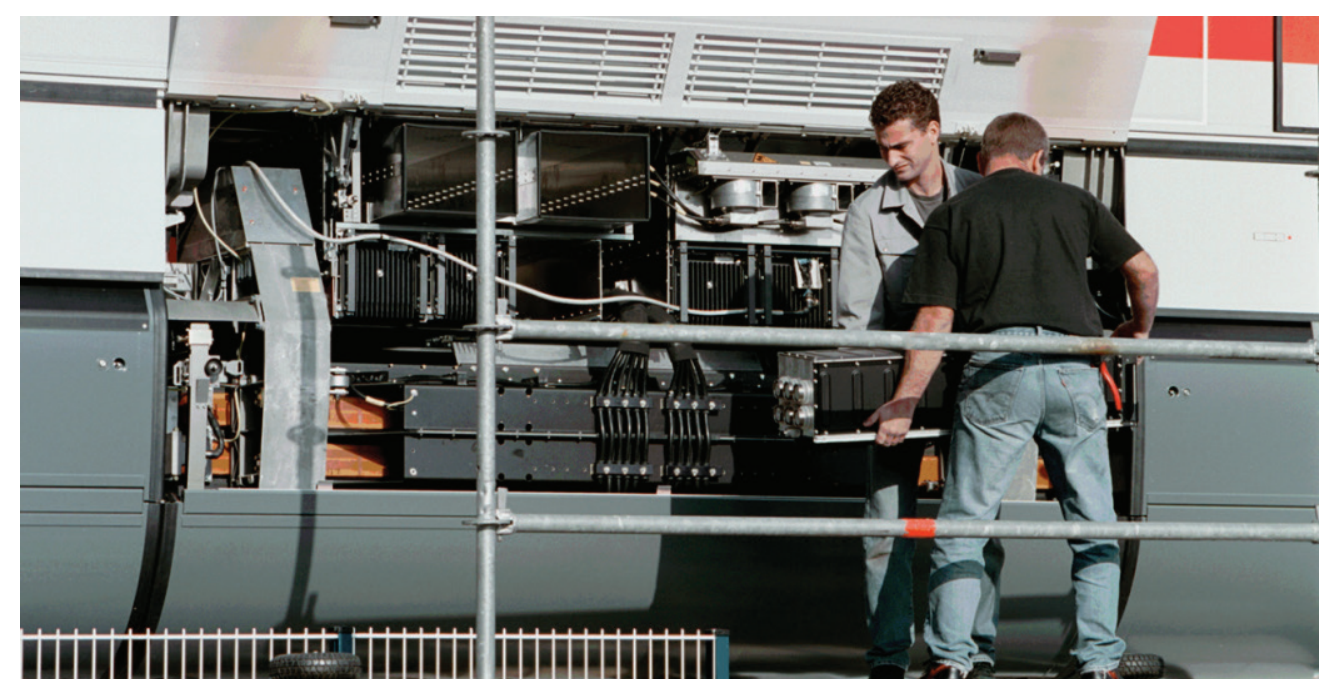

Fig. 3. Exchange of Slide-in Unit 
Independence of subsystems, no relevance of combinations of failures of components of different subsystems, clear definition of structure and components allows assignment of failures to the responsible subsystem

\section{MAINTENANCE STRATEGY AND MEASURES FOR THE VEHICLES}

The maintenance program defines the scheduled and unscheduled maintenance measures required to ensure safety, availability and performance of the system. The maintenance measures are based on fault tree/failure effect/maintenance analysis (including defined mitigation measures), inspection/test results, and manufacturer's specifications for components.

Vehicle maintenance measures executed in the maintenance area are:

- short term maintenance: daily executed measures

- long term maintenance: measures executed in longer time intervals and needing longer time

The technical prerequisites for the status-based maintenance strategy are subsystem diagnosis, failure tolerant, redundant design and inspection procedures.

The long term experience from the Shanghai project has shown that the inspection work that was done in the beginning did not reveal failures before the diagnosis systems disclosed them.

Typical intervals for electronic vehicle components maintenance derived from safety analyses and required to ensure safety of redundant active vehicle functions are daily and annual maintenance.

Scheduled daily vehicle maintenance measures and replacement of defective components can be completed in most cases within a time of maximum 1 hour.

Replacement of a defective electronic unit is expected to occur on the average every two weeks in a 5-car-vehicle with a MTBF target figure of $100000 \mathrm{~h}$ and a total of about 1250 electronic units. The dominant use of slide-in units enables short replacement time of typically below 15 minutes.

\section{NECESSARY SPARE PARTS AND EQUIPMENT FOR VEHICLE MAINTENANCE}

- Set of spare parts to be located in the warehouse of the Maintenance Centre, including a defined amount of complete units, subcomponents and single parts, types and numbers is based on experience with life time, reliability, recovery time and lead time for spare part supply 
- A set of special tools in the Maintenance Centre for assembly on site and execution of required maintenance measures

- Set of maintenance equipment including testing devices to check electronic units and to do inspection items

- Diagnosis database system to receive, transmit and store diagnostic messages, which are sent on-line from cruising vehicles in case of a component failure

\section{THE MAINTENANCE DATA SYSTEMS (MAINTENANCE MANAGEMENT SYSTEM)}

- control data for train movements and safeguarding in the maintenance area

- maintenance program data and maintenance handbook

- diagnostic data display and recording

- line operation display information

- maintenance measures data recording

- configuration data and life cycle of subsystems and components

- spare parts and materials data

\section{DAILY MAINTENANCE}

After arrival of a vehicle in the maintenance center the following steps are carried out:

- complete deactivation of vehicle and shut-down of external power supply, e.g. power rails;

- general visual check, taking about $30 \mathrm{~min}$;

- replacement of defective components;

- daily preventive measures as e.g. exchange or replenishment of operation resources;

- vehicle activation and execution of defined safety-related daily function tests (especially brake test) before restart to station platform to resume scheduled operation.

\section{ANNUAL MAINTENANCE ELECTRONIC COMPONENTS}

Annual scheduled maintenance includes component function tests to detect specific failures. Examples are

- in-circuit measurements; 
- tests of safety-related control functions to check the component's reactions on failure conditions which don't occur and thus can't be detected in regular operation;

- servicing of batteries to restore nominal battery conditions and extend battery lifetime (performed quarterly).

These scheduled annual component tests are carried out at dedicated test benches. The availability of the vehicle for planned operation is only influenced by the necessity to replace the components to be tested by spare parts. This can be done depending on spare part policy and maintenance strategy by

- replacing all vehicle components to be tested (this may need more time on the long term maintenance track, more spare parts and using a long term spare train) or;

- replacement zone by zone or for a defined number of vehicle sections in consecutive night breaks, which also can be done on the short term maintenance track with regular fade-out and fade-in.

\section{ANNUAL MAINTENANCE MECHANICAL COMPONENTS}

Maintenance measures derived for mechanical components are mainly preventive measures carried out in regular intervals. These measures, included in the maintenance program are mainly

- daily visual check as part of daily measures (see above);

- regular inspection, a comprehensive inspections is carried out at the long term maintenance track of the maintenance hall;

- exchange of operating resources like air filters for air-conditioning systems and, if required after five to ten years service life, exchange of minor wearing parts like rubber bearings;

- measurement of geometrical dimensions with respect to defined tolerances.

Long term measures requiring several days are performed after exchange of a vehicle against the long term reserve.

\section{MAINTENANCE PROGRAM AND INSTRUCTIONS}

The maintenance program developed for the vehicles of the Shanghai Maglev Transportation Project consists of maintenance instructions for a total number of about 400 different scheduled and 60 unscheduled measures, including visual checks mostly for longer intervals up to 10 years, function tests, unscheduled 
measures in case of diagnostic message after replacement of the component and replacement of operating resources.

In case of unexpected failures or malfunctions that are not covered by the maintenance routines there is an ongoing cooperation between the operator in Shanghai and the vehicle supplier in Germany. This long term product support is ensured by yearly inspections that are performed together and a steady contact in case of extraordinary events.

\section{CONCLUSION}

The long term experience with maintenance of the Transrapid Maglev in Shanghai shows that the maintenance programs and measures that were defined at the beginning of the project are still valid and sufficient for the safe and reliable function of the system.

The high reliability of the individual components of the vehicle keeps the overall effort low. For the supply of spare parts, the challenge is the design adaptation to the volatile market of electronic components. The necessary lead-time for that adaptation and required qualification has to be considered.

On the side of the vehicle supplier, a small smart team of electronics experts is managing obsolescence and compensates discontinuation.

\section{References}

1. Lin G, Sheng X. Application and Development of Maglev Transportation in China. Proceedings of the $23^{\text {rd }}$ International Conference on Magnetically Levitated Systems and Linear Drives Maglev2016, Vol. 2; 2016 Sep 23-25; Berlin. Berlin: The International MaglevBoard; 2016.

\section{Information about the authors:}

Reinhard Rampelmann,

E-mail: info.transrapid@thyssenkrupp.com

\section{Reiner Köhler,}

E-mail: info.transrapid@thyssenkrupp.com

To cite this article:

Rampelmann R, Köhler R. Service Experiences Maglev Vehicles Shanghai. Transportation Systems and Technology. 2018;4(3):65-71. doi: 10.17816/transsyst20184365-71 